\title{
Dealing with Further Marketing Efforts
}

On the day of the presentation and during the following 48 to 72 hours, the banks will generally pull out all the stops to convey their commitment and will attempt to reach out to the various attendees to whom they have just presented. This will also be made easier by the fact that the banks will now have the business cards of all or most of the representatives on the issuer's side, necessarily seen as the decision makers for their own potential appointment. Accordingly, investment banks will not be shy in using email, sending SMS or calling individuals on their mobile numbers to convey the importance of the mandate to their respective franchises, or to offer reassurances and further insight into their capabilities. Senior people may even turn up uninvited at the door of the CEO or Chief Financial Officer to request a meeting or to ask for feedback on their performance - and redouble their efforts at any inkling that it may not have been up to scratch.

All of the above should be absolutely ignored to avoid complications at a later stage. In beauty parades where an independent adviser or consultant has previously been appointed to assist the issuer and its shareholders, a convenient way of dealing with such requests/ communications is to refer all of these to the adviser for him or her to handle. He or she should, in turn, proceed to purposely ignore all these lobbying efforts or remain strenuously non-committal. 